\title{
(6) OPEN ACCESS \\ Arthroscopic surgery for degenerative knee: systematic review and meta-analysis of benefits and harms
}

\author{
J B Thorlund, ${ }^{1}$ C B Juhl, ${ }^{1,2}$ E M Roos, ${ }^{1}$ LS Lohmander ${ }^{1,3,4}$
}

\begin{abstract}
- Additional material is published online only. To view please visit the journal online (http://dx.doi.org/10.1136/ bjsports-2015-h2747rep)

${ }^{1}$ University of Southern Denmark, Department of Sports Science and Clinical Biomechanics, Campusvej 55, 5230 Odense M, Denmark ${ }^{2}$ Department of Orthopedics, Copenhagen University Hospital, Gentofte, Denmark ${ }^{3}$ Department of Orthopedics and Traumatology, Odense University Hospital, Odense, Denmark

${ }^{4}$ Department of Orthopedics, Clinical Sciences Lund University of Lund, Sweden
\end{abstract}

Correspondence to J B Thorlund; jthorlund@health.sdu.dk

Accepted 22 April 2015

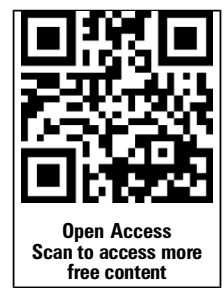

CrossMark

To cite: Thorlund $\mathrm{JB}$,

Juhl CB, Roos EM, et al. Br J

Sports Med 2015;49:

1229-1235.
ABSTRACT

Objective To determine benefits and harms of arthroscopic knee surgery involving partial meniscectomy, debridement, or both for middle aged or older patients with knee pain and degenerative knee disease.

Design Systematic review and meta-analysis.

Main outcome measures Pain and physical function.

Data sources Systematic searches for benefits and harms were carried out in Medline, Embase, CINAHL, Web of Science, and the Cochrane Central Register of Controlled Trials (CENTRAL) up to August 2014. Only studies published in 2000 or later were included for harms.

\section{Eligibility criteria for selecting studies}

Randomised controlled trials assessing benefit of arthroscopic surgery involving partial meniscectomy, debridement, or both for patients with or without radiographic signs of osteoarthritis were included. For harms, cohort studies, register based studies, and case series were also allowed.

Results The search identified nine trials assessing the benefits of knee arthroscopic surgery in middle aged and older patients with knee pain and degenerative knee disease. The main analysis, combining the primary endpoints of the individual trials from three to 24 months postoperatively, showed a small difference in favour of interventions including arthroscopic surgery compared with control treatments for pain (effect size $0.14,95 \%$ confidence interval 0.03 to 0.26 ). This difference corresponds to a benefit of $2.4(95 \%$ confidence interval 0.4 to 4.3$) \mathrm{mm}$ on a $0-100 \mathrm{~mm}$ visual analogue scale. When analysed over time of follow-up, interventions including arthroscopy showed a small benefit of 3-5 $\mathrm{mm}$ for pain at three and six months but not later up to 24 months. No significant benefit on physical function was found (effect size $0.09,-0.05$ to 0.24 ). Nine studies reporting on harms were identified. Harms included symptomatic deep venous thrombosis (4.13 (95\% confidence interval 1.78 to 9.60 ) events per 1000 procedures), pulmonary embolism, infection, and death.

Conclusions The small inconsequential benefit seen from interventions that include arthroscopy for the degenerative knee is limited in time and absent at one to two years after surgery. Knee arthroscopy is associated with harms. Taken together, these findings do not support the practise of arthroscopic surgery for middle aged or older patients with knee pain with or without signs of osteoarthritis.

Systematic review registration PROSPERO CRD42014009145.

\section{INTRODUCTION}

Arthroscopic knee surgery with meniscus resection is common for middle aged or older people with persistent knee pain. ${ }^{1-3}$ The knees of these patients often show "degenerative" lesions of cartilage, meniscus, and other tissues, suggestive of osteoarthritis. However, population based studies using magnetic resonance imaging show that incidental findings of such lesions are also very common among people without knee symptoms and among those without plain radiographic signs of osteoarthritis, suggesting that the clinical significance of such findings is unclear. ${ }^{4-6}$ All but one of the nine randomised clinical trials to date of arthroscopic surgery in middle aged or older people with persistent knee pain failed to show an added benefit of interventions including arthroscopic surgery over a variety of control treatments. ${ }^{7-15}$ Uncertainty thus exists about the benefit of arthroscopic surgery including meniscus resection for these patients. However, many specialists are convinced of the benefits of the procedure from their own experience, ${ }^{16-19}$ and several recent reports show an increase, or no decrease, in the incidence of arthroscopic knee surgery with meniscus resection during the past decade. ${ }^{320-23}$ The arthroscopic procedures discussed here are reported to be associated with adverse events, including deep venous thrombosis, infections, cardiovascular events, pulmonary embolism, and death. ${ }^{24-26}$

The balance of benefits and harms weighs importantly in the choice of treatment. To inform the choice of treatment for these patients, we did a comprehensive, up to date systematic review and meta-analysis of the benefits and harms of arthroscopic surgery compared with control treatments for middle aged and older people with persistent knee pain. We extend existing knowledge by including more patients and by presenting outcomes on pain, function, and harms in patients ranging from those with degenerative meniscal tears and no radiographic signs of osteoarthritis to those with degenerative meniscal tears and more severe signs of osteoarthritis. We also accounted for the study designs used and, when appropriate, did a priori defined subgroup analyses.

\section{METHODS}

We used the preferred reporting items for systematic reviews and meta-analyses (PRISMA) statement as a guideline for this study. ${ }^{27}$ 


\section{Eligibility criteria}

We included randomised controlled trials assessing the benefits (pain and physical function) of arthroscopic surgery involving partial meniscectomy, debridement, or both for patients with or without osteoarthritis compared with non-surgical treatments such as sham surgery (including lavage), exercise, and medical treatment. Our aim was to include studies on middle aged and older patients, but we applied no restriction on age in the search as degenerative knee disease is rare before middle age. We excluded studies on patients with concomitant cruciate ligament injuries. For the search on harms, we also allowed cohort studies, register based studies, and case series, again excluding studies on patients with concomitant cruciate ligament injuries.

\section{Literature search and study selection}

We did systematic searches for benefits and harms in Medline, Embase, CINAHL, Web of Science, and the Cochrane Central Register of Controlled Trials (CENTRAL) in April 2014 and updated them in August 2014. Owing to advances in surgical and anaesthetic procedures over time, we included only studies published in 2000 or later for harms. We adjusted the search strategies according to the specifications of the individual database (see web appendix). We set no search restrictions for follow-up time, patients' age, study size, or language. Two members of the study team independently assessed all titles and abstracts of identified reports for eligibility (benefits: JBT and CBJ; harms: JBT and LSL). We obtained the full text if at least one of the reviewers judged a study to be eligible. We reviewed reference lists of included studies to identify additional studies. Disagreements on inclusion were resolved by consensus.

\section{Data extraction}

The pre-specified outcomes for benefits were patient reported pain and physical function. When a report provided data on more than one pain or physical function scale, we used a published hierarchy for selection of patient reported outcomes (please refer to the PROSPERO protocol). ${ }^{28}$ We extracted outcomes for all reported follow-up assessments in the included studies.

For the primary analysis on pain and physical function, we used data from the primary follow-up time as defined in the individual studies, varying from three to 24 months. If a study did not explicitly state a primary follow-up time, we included the longest follow-up time from the initial trial report in the primary analysis. We extracted the standard deviation or estimated it from the confidence interval, the $\mathrm{P}$ value, or the interquartile range or used other methods recommended by the Cochrane Handbook for Systematic Reviews. ${ }^{29}$ If necessary, we approximated means and measures of dispersion from figures in the included studies.

In addition to the outcomes specified above, we extracted the number of participants allocated to intervention and control groups, distribution of sex, mean age at baseline, body mass index at baseline, baseline pain (transformed into a visual analogue pain scale from 0 to $100 \mathrm{~mm}$ ), and interventions performed in the intervention and control groups. We also extracted data on the presence or absence of radiographic knee osteoarthritis in the study populations. As some studies included patients both with and without radiographic knee osteoarthritis, we divided the studies into three subgroups on the basis of the population included: no radiographic knee osteoarthritis population (that is, all patients had Kellgren and Lawrence grade 0 or $1^{3}$ ); radiographic knee osteoarthritis population (that is, all patients had Kellgren and Lawrence grade 2 or higher); and mixed population (some patients with and some without radiographic knee osteoarthritis). For studies using the Ahlbäck scale for defining radiographic knee osteoarthritis, ${ }^{31}$ we considered a grade of 0 as no radiographic knee osteoarthritis and grade 1 or higher as radiographic knee osteoarthritis.

We extracted all adverse events reported. However, we had decided a priori to do meta-analysis only on the following adverse events: deep venous thrombosis, pulmonary thromboembolism, venous thromboembolism, infection, and death (all cause mortality). We chose these adverse events on the basis of a preliminary search and their seriousness and frequency. If a study did not report the rate of venous thromboembolism but reported both deep venous thrombosis and pulmonary thromboembolism, we combined the last two to generate a venous thromboembolism variable for meta-analysis.

In addition to adverse events, we registered the study design, mode of reporting (that is, per patient or per procedure), sample size, period of adverse events collection, types of adverse events, and number of adverse events. We used customised forms to independently extract all data for benefits (JBT, $\mathrm{CBJ}$ ) and harms (JBT, CBJ, LSL).

\section{Synthesis of results}

For the analysis on benefits, we calculated the effect sizes in the individual studies as standardised mean differences, allowing pooling and comparison of the various outcomes assessed in the individual trials. We estimated the standardised mean difference as the difference between the mean score of the intervention and control groups divided by the pooled standard deviation of the final score. This estimate of the effect size using standardised mean difference has a slight bias overestimating the effect size, and we applied a correction factor to convert the effect size to Hedges' g. ${ }^{32}$

We used meta-analysis to combine the individual study results by using the Stata software package (version 13.0). We applied the REstricted Maximum Likelihood (REML) method to estimate the combined effect size and the between study variance. We examined heterogeneity between trials with Q tests and calculated the $\mathrm{I}^{2}$ statistic, $^{33}$ measuring the proportion of variation (that is, inconsistency) in the combined estimates due to between study heterogeneity. ${ }^{34}$ We transformed the effect size measured as standardised mean difference into a visual analogue scale ranging from 0 to $100 \mathrm{~mm}$ by multiplying it by a standard deviation equal to $16.9 \mathrm{~mm}$ for pain and $16.6 \mathrm{~mm}$ for physical function. ${ }^{35}$ The standard deviations used for conversion of standardised mean difference to millimetres were based on a cohort of 914 patients with knee osteoarthritis. ${ }^{36}$ Furthermore, we used the formula proposed by Chinn in the Cochrane Handbook to estimate the odds ratio and number needed to treat. $^{35-38}$

We analysed the effect of arthroscopic surgery involving partial meniscectomy, debridement, or both for patient reported pain and physical function. We did subgroup analyses to explore the effect of severity of degenerative knee disease defined by presence of radiographic knee osteoarthritis in the respective study populations (no patients with radiographic knee osteoarthritis, patients with or without radiographic knee osteoarthritis, or all patients with radiographic knee osteoarthritis), the effect of partial meniscectomy with or without concomitant debridement, risk of bias, and type of study design. To investigate whether the results were dependent on follow-up time, we also did meta-analysis on all available follow-up time points with at least two studies available. 
In the analysis on harms, we transformed the numbers of adverse events into log odds of events, allowing pooling of data from the individual studies. Results are reported as number of adverse events per 1000 procedures with 95\% confidence intervals. We applied a REML method to estimate the combined odds of events and the between study variance. We assessed study heterogeneity by calculating the $\mathrm{I}^{2}$ statistic.

\section{Risk of bias assessment}

Two reviewers (JBT and CBJ) independently assessed risk of bias by using the Cochrane Handbook for Systematic Reviews of Interventions. ${ }^{29}$ For studies on benefits, the two reviewers independently assessed sequence generation, allocation concealment, blinding, handling of incomplete outcome data, selective outcome reporting, and other bias. For harms, they assessed each of the included studies for description of intervention, type of adverse events reported, and loss to follow-up. Each of the domains was scored as "adequate," "inadequate," or "unclear." Disagreements were resolved by consensus. For a full elaboration on the criteria for each of the bias assessment domains, please refer to the study protocol (PROSPERO registration number CRD42014009145).

\section{Patient involvement}

There was no patient involvement in this study.

\section{RESULTS}

\section{Benefits}

The literature search yielded 1789 reports after exclusion of duplicates. Of these, 18 were considered for inclusion after review of title and abstract. After full text review, six reports were excluded because of no or insufficient data on patient reported pain or physical function, ${ }^{39-44}$ and two were excluded because they were not clinical trial reports. ${ }^{45} 46$ We included 10 reports on nine different trials in the systematic review (supplementary figure A). ${ }^{7-14} 47$ One report was not included in the final meta-analysis as it was a secondary trial report and the only one providing five year follow-up data. ${ }^{47}$

\section{Study characteristics}

The nine included trials had randomly allocated 1270 patients to interventions including arthroscopic surgery with partial meniscectomy, debridement, or both or a variety of control treatments ranging from placebo surgery to exercise (supplementary table A). Mean age of patients in the individual trials ranged from 49.7 to 62.8 years. Mean baseline pain in the included studies ranged from 36 to $63 \mathrm{~mm}$ on a $0-100 \mathrm{~mm}$ visual analogue scale. In two trials, ${ }^{8} 10$ all patients had radiographic knee osteoarthritis (Kellgren and Lawrence grade 2 or more); in five trials, ${ }^{7} 911121547$ some of the patients had radiographic knee osteoarthritis; and in two trials, ${ }^{13}{ }^{14}$ no patients had radiographic knee osteoarthritis. The follow-up time for the primary endpoint in the trials varied between three and 24 months.

\section{Synthesis of results}

Our primary analysis for pain, combining the individual trials' primary endpoints ranging from three to 24 months, showed a small but statistically significant benefit for interventions including knee arthroscopy compared with control treatments (effect size $0.14,95 \%$ confidence interval 0.03 to $0.26 ; \mathrm{I}^{2}=0.0 \%$ ) (figure 1 and supplementary table B). This effect size corresponds to a difference of 2.4 (95\% confidence interval 0.4 to 4.3) $\mathrm{mm}$ between treatment groups on a $0-100 \mathrm{~mm}$ visual analogue scale. Evaluation of between group differences at different postoperative time points showed a statistically significant benefit in favour of interventions including knee arthroscopy at three months (effect size $0.27,0.14$ to $0.41 ; \mathrm{I}^{2}=20.6 \%$ ) and six months $\left(0.18,0.05\right.$ to $\left.0.30 ; \mathrm{I}^{2}=0.0 \%\right)$ but not at later postoperative times (figure 2 and supplementary table B).

For physical function, we found no significant difference between interventions including knee arthroscopy and control treatments (effect size $0.09,-0.05$ to $0.24 ; \quad I^{2}=11.9 \%$ ) (figure 3). When evaluating physical function over time, we found no between group differences at any of the analysed time points (figure 4).

\section{Risk of bias}

Agreement between assessors on risk of bias ranged from $78 \%$ to $100 \%$ (that is, $\kappa$ values ranging from 0.53 to 1.00 ). Only one included report was assessed as "adequate" on all domains (supplementary table C), ${ }^{14}$ and only two reports were assessed as "adequate" for blinding. ${ }^{8} 14$ The remaining studies were not blinded. $^{79-131547}$

\section{Subgroup analysis}

Analysis of the effect of risk of bias showed no differences between studies scored as adequate, unclear, or inadequate on any of the domains investigated (figure 5 and supplementary figure B). We also did subgroup analyses on the primary endpoint analysis of pain and physical function for the osteoarthritis status of the study population (ranging from no
Figure 1 Results of primary analysis on benefit on patient reported pain of interventions including arthroscopic knee surgery compared with control interventions (follow-up time range: 3-24 months).

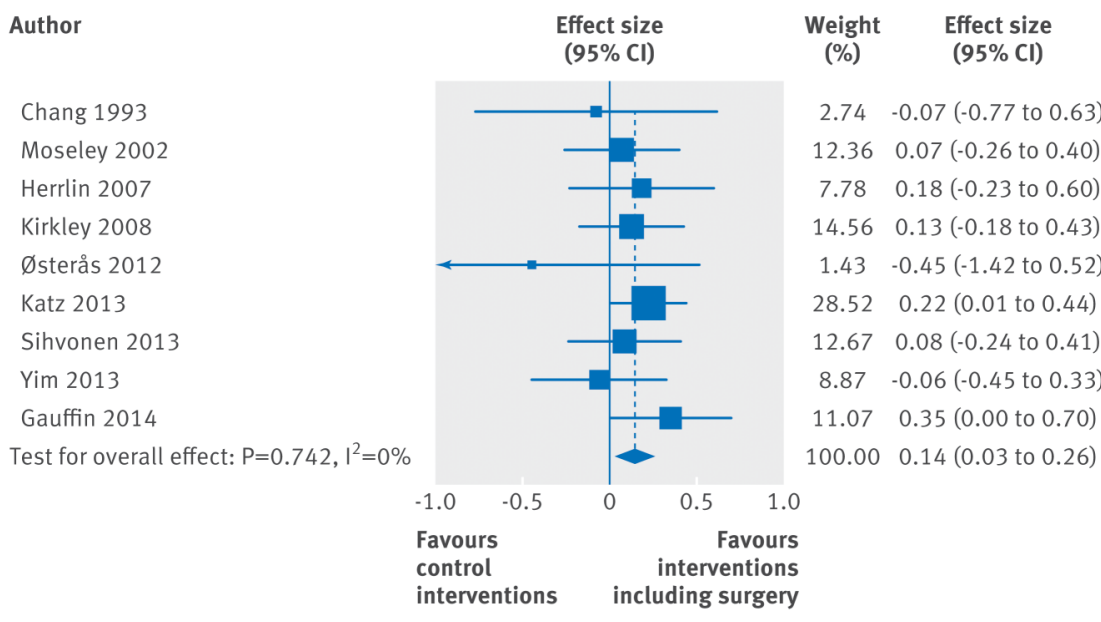


Figure 2 Effect of interventions including arthroscopic knee surgery compared with control interventions on patient reported pain presented as difference in $\mathrm{mm}$ on $0-100 \mathrm{~mm}$ visual analogue scale, with $95 \%$ confidence interval error bars. Table below shows number of studies and patients included in analyses at different follow-up time points, with estimated difference between interventions calculated as effect size and estimates of heterogeneity $\left(\mathrm{I}^{2}\right)$. Data from 2 months' follow-up from Osteraas et $\mathrm{al}$ and Sihvonen et al are included in 3 month estimate.

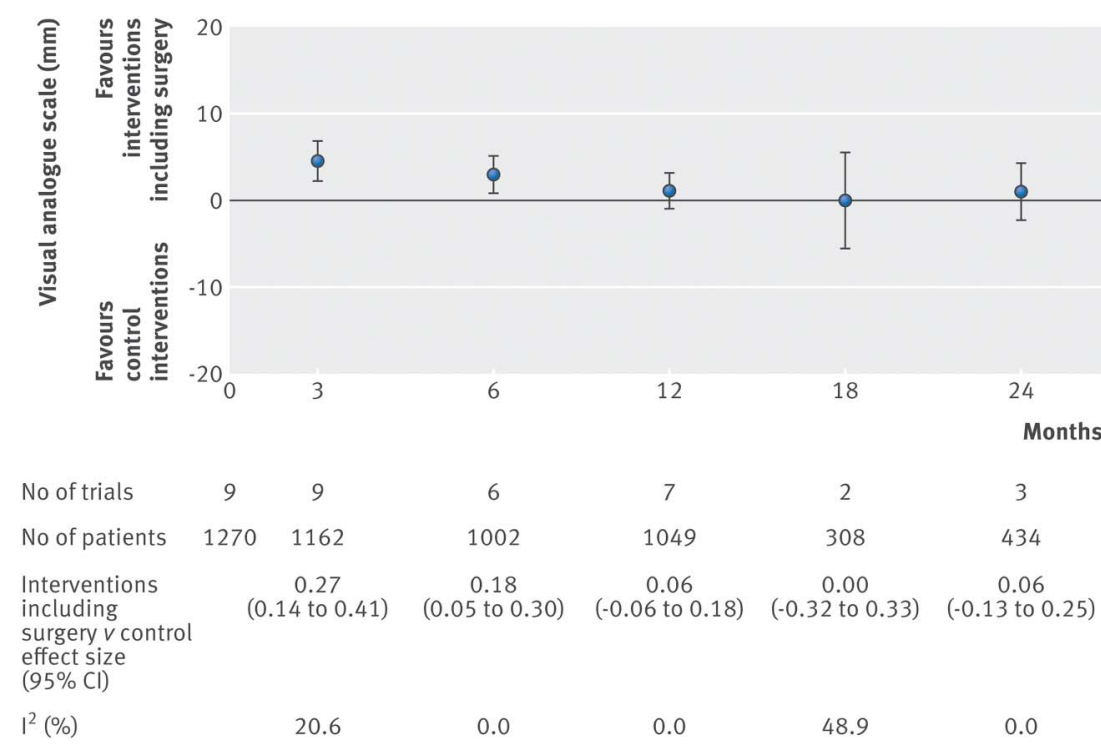

radiographic osteoarthritis at all via a mixed population to all having radiographic osteoarthritis) and for type of surgery (partial meniscectomy with or without concomitant debridement) (figure 6 and supplementary figure C). These analyses did not change the interpretation of the results from the primary analyses. Subgroup analysis stratified for presence/absence of mechanical symptoms was not possible owing to lack of data. In a further subgroup analysis to evaluate the influence of study design, we found no differences between studies with different control interventions (figure 6 and supplementary figure C).

\section{Harms}

We screened titles and abstracts of 2330 reports after exclusion of duplicates; of these, 37 were reviewed as full text. This resulted in exclusion of 28 reports, ${ }^{48-75}$ leaving nine reports for meta-analysis (supplementary figure A). ${ }^{12} 14$ 24-26 76-79

\section{Study characteristics}

Two randomised trials and seven observational/registry studies reported on adverse events (supplementary table D). ${ }^{12} 14$ 24-26 ${ }_{76-79}$ Quality of reporting of adverse events was frequently low in both observational studies and randomised clinical trials, and only two of nine arthroscopy trials provided useful information on adverse events.

\section{Synthesis of results}

Deep venous thrombosis was the most frequently reported symptomatic adverse event associated with arthroscopic meniscectomy, with 4.13 (95\% confidence interval 1.78 to 9.60) events per 1000 procedures, followed by infection, pulmonary embolism, and death (table 1 and supplementary table B). Heterogeneity of all the estimates was high (table 1 ).

Risk of bias

Only one study was assessed as "adequate" on all three domains (supplementary table E). ${ }^{12}$ All reports sufficiently described the surgical intervention, but seven of nine studies reported only a few types of adverse events in the same report (supplementary table D).

\section{DISCUSSION}

In this meta-analysis, in which the primary endpoint of each of the nine included randomised trials ranged from three to 24 months after surgery, we found a small but statistically significant effect on pain relief from interventions including arthroscopic surgery compared with control treatments, corresponding to a $2.4 \mathrm{~mm}$ between group difference on a $0-100 \mathrm{~mm}$ visual analogue scale. When we analysed pain for different postoperative time points, the benefit favouring arthroscopic surgery was present only at three and six months, but not at later time points. We found no between group differences for self reported physical function in any of the analyses. Deep venous thrombosis was the most frequently reported symptomatic adverse event, followed by infection, pulmonary embolism, and death.
Figure 3 Results of main analysis on benefit on patient reported physical function of interventions including arthroscopic knee surgery compared with control interventions (follow-up time range: 3-24 months).

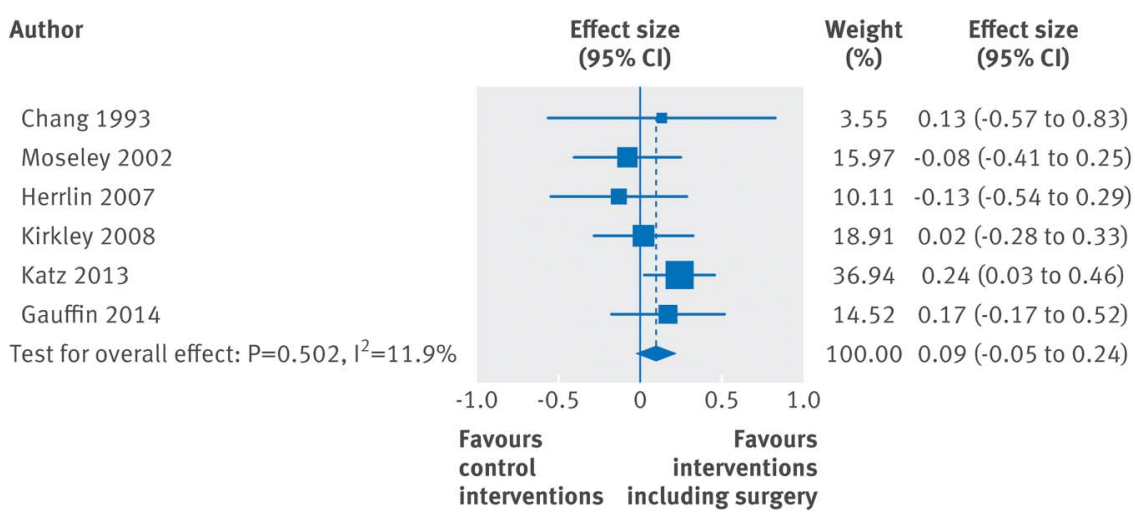

Thorlund JB, et al. Br J Sports Med 2015;49:1229-1235. doi:10.1136/bjsports-2015-h2747rep 
Figure 4 Effect of interventions including arthroscopic knee surgery compared with control interventions on patient reported physical function presented as difference in $\mathrm{mm}$ on 0-100 mm visual analogue scale, with $95 \%$ confidence interval error bars. Table below shows number of studies and patients included in analyses at the different follow-up time points, with estimated difference between and estimates of heterogeneity $\left(\mathrm{I}^{2}\right)$. interventions calculated as effect size

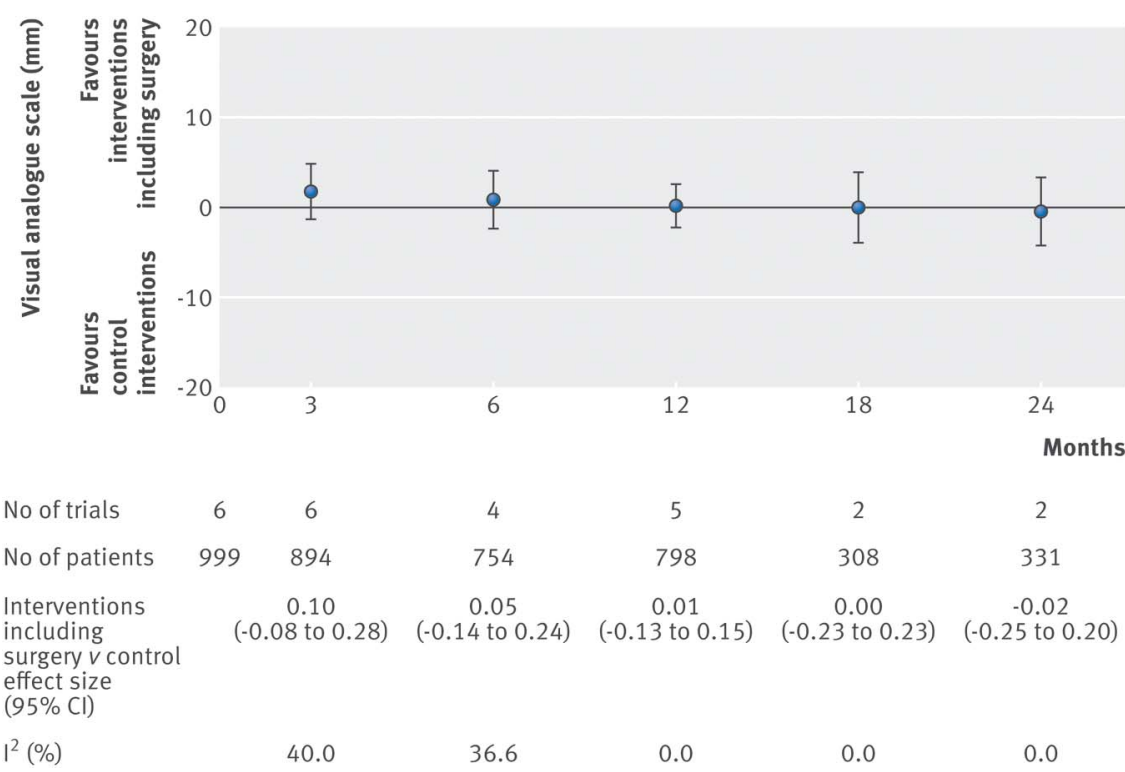

\section{Strengths and weaknesses}

Previous systematic reviews have investigated the benefits of knee arthroscopy in patients with established knee osteoarthritis or no/mild knee osteoarthritis. ${ }^{80} 81$ To the best of our knowledge, ours is the first systematic review and meta-analysis to include both benefits and harms of arthroscopic surgery and to include the whole continuum of degenerative knee disease, ranging from patients with degenerative meniscal tears without radiographic changes to those with meniscal tears and other joint changes combined with more severe radiographic changes. We included all identified randomised controlled trials of arthroscopic surgery for the degenerative knee comparing interventions including arthroscopic surgery with control treatments. To facilitate interpretation of pain and function results, we based our analysis on patient reported pain and function. Composite measures of "knee function," aggregating arbitrarily weighted more or less correlated items into one score, are notoriously difficult to interpret and were therefore not included. We also searched the literature for information on harms associated with this intervention, and we included observational studies published from 2000 onwards. The individual trials from different countries and populations showed consistent results, with low heterogeneity for benefit, whereas heterogeneity for harms was large.

Only two of the nine arthroscopy trials were adequate for blinding, and these trials included a control group with sham surgery. Many of the other trials, being inadequately blinded and using control groups with various non-invasive treatments, were assessed according to the Cochrane Collaboration criteria as having a high risk of bias. ${ }^{29}$ Given that invasive procedures have a stronger placebo effect than do non-invasive ones, the resulting bias from inadequate or absent blinding would be expected to favour the treatment arm including arthroscopic surgery. ${ }^{82,85}$

The focus of five of the nine trials was, by study design, on the additional benefit from arthroscopic surgery when the same
Figure 5 Evaluation of risk of bias in primary analysis of pain. $P$ value indicates difference between studies dependent on risk of bias scoring (that is, adequate, inadequate, and unclear).

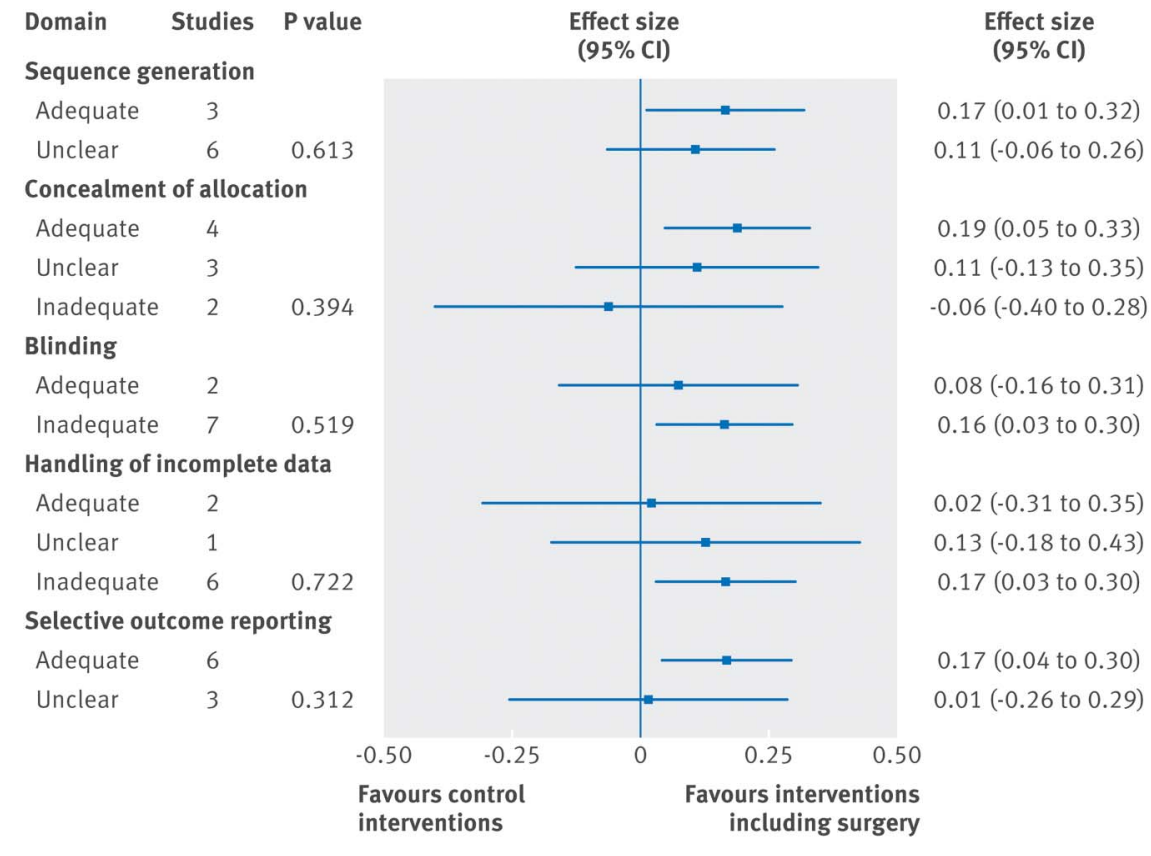


Figure 6 Subgroup analysis on primary analysis of pain stratified by study population knee osteoarthritis status, surgery type, and study design. $P$ value indicates difference between different subgroups.

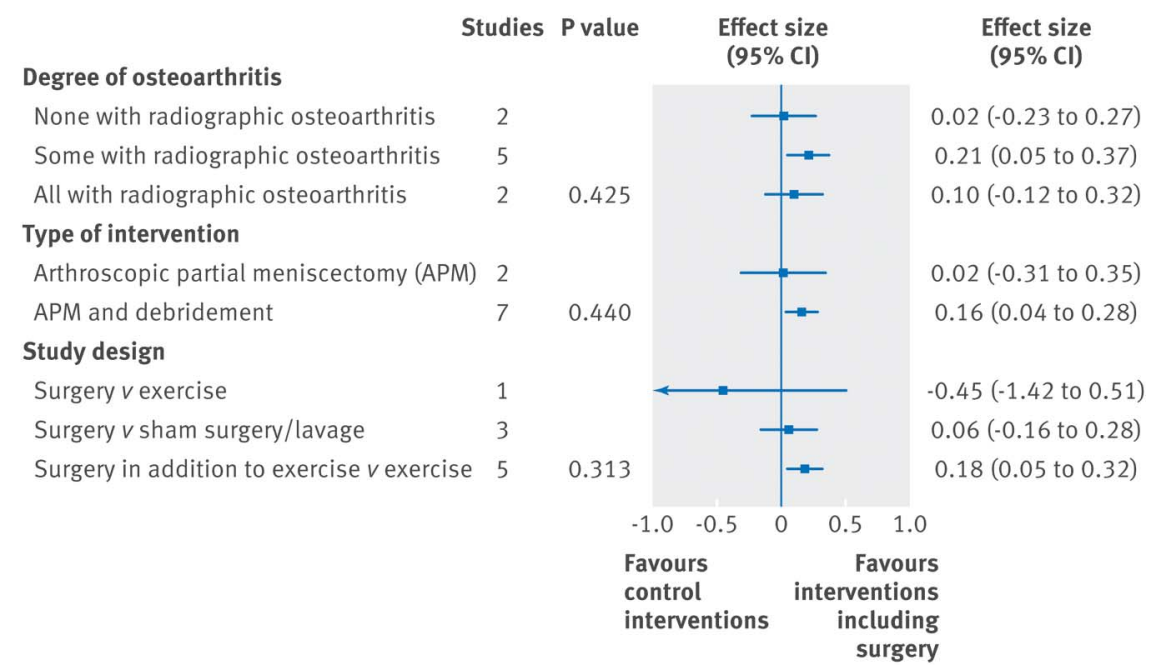

non-surgical intervention was provided to both the intervention and comparator group. The exercise therapy component, applied both in the intervention and in the comparator arms, was in many cases of inadequate dose for an optimal efficacy or poorly described. ${ }^{86}$ In light of our incomplete understanding of the possible interaction between exercise therapy and a surgical intervention and their resulting combined efficacy, compared with the efficacy of exercise therapy in isolation, the resulting direction of bias is uncertain.

The randomised controlled trials of arthroscopic surgery were small, limiting their usefulness in assessing harms, and most of them provided no useful information on adverse events. We therefore included observational studies to obtain information on harms associated with arthroscopic surgery involving meniscectomy, debridement, or both. ${ }^{87}$ The heterogeneity for assessing harms was high, reflecting differences in study size and design and quality of reporting of adverse events. Generally, the terminology and consistency in reporting of adverse events was poor. We did not systematically search the literature for harms associated with the control treatments, notably exercise. However, serious adverse events seem to be rare whereas minor events related to joint pain and muscle soreness are commonly reported from resistance training, including from patients with knee osteoarthritis. ${ }^{88}$

\section{Meaning of study}

The overall additional benefit on pain from arthroscopic surgery, using the primary endpoint of each trial, was small (effect size 0.14 ) and limited in time. This benefit is comparable to the small pain relieving effect on knee pain seen from

Table 1 Summary of meta-analysis on harms of arthroscopic meniscectomy

\begin{tabular}{llll}
\hline & $\begin{array}{l}\text { No of studies } \\
\text { (No of patients/ } \\
\text { procedures) }\end{array}$ & $\begin{array}{l}\text { No of adverse } \\
\text { events per } 1000^{*} \\
\text { (95\% Cl) }\end{array}$ & $\mathbf{I}^{2}(\%)$ \\
\hline Deep venous thrombosis & $5(432663)$ & $4.13(1.78$ to 9.60$)$ & 98.3 \\
Pulmonary embolism & $6(736823)$ & $1.45(0.59$ to 3.54$)$ & 98.6 \\
Venous thromboembolism & $6(571793)$ & $5.68(2.96$ to 10.9$)$ & 99.3 \\
Infection & $4(946230)$ & $2.11(0.80$ to 5.56$)$ & 99.6 \\
Death & $2(106967)$ & $0.96(0.04$ to 23.9$)$ & 90.3 \\
\hline${ }^{*}$ Mix of studies reporting per patient and per procedure.
\end{tabular}

paracetamol (effect size 0.14), less than that of non-steroidal anti-inflammatory drugs (0.29), ${ }^{89}$ and markedly smaller than the moderate to large pain relieving effect seen from exercise therapy as treatment for knee osteoarthritis (overall standardised mean difference 0.50 regardless of type or dose, or 0.68 for exercise performed three times a week). ${ }^{86}$ A previous systematic review and meta-analysis of benefits of arthroscopy suggested that a clinically relevant improvement for arthroscopic surgery in this patient group would correspond to a standardised mean difference of $0.45 .{ }^{81}$ Effect sizes can be difficult to interpret, so we converted them to $\mathrm{mm}$ on a $0-100$ visual analogue scale. The effect size of 0.14 corresponds to difference of $2.4 \mathrm{~mm}$. This is a negligible difference on a $0-100$ scale and much smaller than the $15-20 \mathrm{~mm}$ commonly suggested as representing a clinically relevant difference for pain. ${ }^{90}$ Claims of benefit in subgroups of patients are not supported by published evidence.

We observed a substantial improvement in the intervention group receiving surgery, corresponding to the clinical impression of many surgeons. ${ }^{16-19}$ Accordingly, recent reports show an increase, or no decrease, in the incidence of arthroscopic knee surgery in middle aged or older people with persistent knee pain. ${ }^{3}{ }^{20-23}$ However, the improvements in the control groups were similarly impressive, with no clinically relevant between group differences at any time point. This is in line with a recent systematic review of the use of placebo controls in the evaluation of surgery, with considerable improvement in placebo arms of randomised trials and similar or only marginally superior benefit from surgery in half of the included studies. ${ }^{91} 92$

Arthroscopic meniscectomy is associated with short term risk of harms, of which the most common was deep venous thrombosis, and in rare cases death. Arthroscopic meniscus resection may also be associated with long term harms. Resection of the meniscus increases local contact pressures in the knee, increasing the risk for development of osteoarthritis. ${ }^{93-95}$ In support, patients with previous knee surgery undergo total knee arthroplasty at a significantly younger age than do patients without previous knee surgery. ${ }^{96}$

Arthroscopic surgery in the middle aged and older population with knee pain represents most arthroscopies and is routinely performed on the basis of a suspected meniscal tear by clinical examination or as diagnosed by magnetic resonance imaging, the reasoning being that the pain is associated with the meniscal tear. However, meniscal tears and other structural abnormalities (such as osteophytes, cartilage damage, and bone marrow lesions) are characteristics of knee osteoarthritis, often coexist, 
and are common findings in painful knees but also commonly occur in pain-free knees in middle aged and older people..$^{5} 6$ Such joint damage is often present without a history of distinct trauma but is considered to be of a "degenerative" nature and indicative of early knee osteoarthritis. ${ }^{5}$ Thus, middle aged patients with knee pain and meniscal tears should be considered as having early stage osteoarthritis and be treated according to clinical guidelines for knee osteoarthritis, starting with information, exercise, and often weight loss. ${ }^{97}$

\section{Unanswered questions and future research}

Available evidence supports the reversal of a common medical practice. ${ }^{98}$ However, disinvestment of commonly used procedures remains a challenge, and use of arthroscopy seems to be undiminished, in analogy with use of vertebroplasty following the publication of trials showing absence of benefit of this procedure. $^{98} 99$ Surgeon confirmation bias in combination with financial aspects and administrative policies may be factors more powerful than evidence in driving practice patterns. ${ }^{23} 100-103$

\section{What is already known on this topic}

- Arthroscopic knee surgery is frequently and increasingly used to treat middle aged and older patients with persistent knee pain

- All but one published randomised trials have shown no added benefit for arthroscopic surgery over that of the control treatment, but many specialists are convinced of the benefits of the surgical intervention

\section{What this study adds}

- Interventions that include arthroscopy are associated with a small benefit and with harms; the small benefit is inconsequential and of short duration

- The benefit is markedly smaller than that seen from exercise therapy as treatment for knee osteoarthritis

- These findings do not support the practice of arthroscopic surgery as treatment for middle aged or older patients with knee pain with or without signs of osteoarthritis

Acknowledgements We thank senior biostatistician and professor of clinical epidemiology Robin Christensen for his assistance with the statistical analysis.

Contributors JBT, CBJ, EMR, and LSL all participated in the conception and design of the study. JBT, CBJ, and LSL were responsible for acquisition of data. CBJ did the analysis, and JBT, EMR, and LSL took part in the interpretation of the analysis. JBT and LSL drafted the manuscript. All authors critically revised the manuscript for important intellectual content and approved the final version of the manuscript. LSL is the guarantor.

Funding LSL is supported by the Swedish Research Council.The funder had no role in any part of the study or in any decision about publication.

Competing interests LSL has received personal fees from Össur, Flexion Therapeutics, Medivir, Teijin, MerckSerono, Allergan, and Galapagos and is editor-in-chief of Osteoarthritis and Cartilage; EMR has received personal fees for lectures and royalties for books from Össur, Finnish Orthopedic Society,

Studentlitteratur, and Munksgaard and is an associate editor of Osteoarthritis and Cartilage; no other relationships or activities that may appear to have influenced the submitted work.

Ethical approval Not required.
Data sharing Statistical code and dataset are available from the corresponding author.

Open Access This is an Open Access article distributed in accordance with the Creative Commons Attribution Non Commercial (CC BY-NC 4.0) license, which permits others to distribute, remix, adapt, build upon this work non-commercially, and license their derivative works on different terms, provided the original work is properly cited and the use is non-commercial. See: http://creativecommons.org/ licenses/by-nc/4.0/

\section{REFERENCES}

1 Hawker G, Guan J, Judge A, et al. Knee arthroscopy in England and Ontario: patterns of use, changes over time, and relationship to total knee replacement. J Bone Joint Surg Am 2008:90:2337-45.

2 Cullen K, Hall M, Golosinskiya A. Ambulatory surgery in the United States, 2006. National Center for Health Statistics, 2009.

3 Lazic S, Boughton O, Hing C, et al. Arthroscopic washout of the knee: a procedure in decline. Knee 2014;21:631-4.

4 Englund M, Niu J, Guermazi A, et al. Effect of meniscal damage on the development of frequent knee pain, aching, or stiffness. Arthritis Rheum 2007:56:4048-54.

5 Englund M, Guermazi A, Gale D, et al. Incidental meniscal findings on knee MRI in middle-aged and elderly persons. N Engl I Med 2008;359:1108-15.

6 Guermazi A, Niu J, Hayashi D, et al. Prevalence of abnormalities in knees detected by MRI in adults without knee osteoarthritis: population based observational study (Framingham Osteoarthritis Study). BMJ 2012;345:e5339.

7 Chang RW, Falconer J, Stulberg SD, et al. A randomized, controlled trial of arthroscopic surgery versus closed-needle joint lavage for patients with osteoarthritis of the knee. Arthritis Rheum 1993;36:289-96.

8 Moseley JB, O'Malley K, Petersen NJ, et al. A controlled trial of arthroscopic surgery for osteoarthritis of the knee. N Engl J Med 2002;347:81-8.

9 Herrlin $S$, Hallander M, Wange $P$, et al. Arthroscopic or conservative treatment of degenerative medial meniscal tears: a prospective randomised trial. Knee Surg Sports TraumatolArthrosc 2007;15:393-401.

10 Kirkley A, Birmingham TB, Litchfield RB, et al. A randomized trial of arthroscopic surgery for osteoarthritis of the knee. N Engl J Med 2008;359:1097-107

11 Osteras H, Osteras B, Torstensen TA. Medical exercise therapy, and not arthroscopic surgery, resulted in decreased depression and anxiety in patients with degenerative meniscus injury. J BodywMov Ther 2012;16:456-63.

12 Katz JN, Brophy RH, Chaisson CE, et al. Surgery versus physical therapy for a meniscal tear and osteoarthritis. N Engl J Med 2013:368:1675-84.

13 Yim JH, Seon JK, Song EK, et al. A comparative study of meniscectomy and nonoperative treatment for degenerative horizontal tears of the medial meniscus. Am J Sports Med 2013;41:1565-70.

14 Sihvonen R, Paavola M, Malmivaara A, et al. Arthroscopic partial meniscectomy versus sham surgery for a degenerative meniscal tear. $N$ Engl I Med 2013;369:2515-24.

15 Gauffin H, Tagesson S, Meunier A, et al. Knee arthroscopic surgery is beneficial to middle-aged patients with meniscal symptoms: a prospective, randomised, single-blinded study. Osteoarthritis Cartilage 2014;22:1808-16.

16 Elattrache N, Lattermann C, Hannon M, et al. New England Journal of Medicine article evaluating the usefulness of meniscectomy is flawed. Arthroscopy 2014;30:542-3.

17 Krych AJ, Stuart MJ, Levy BA. Arthroscopic partial meniscectomy for degenerative meniscal tear. N Engl J Med 2014;370:1259.

18 Rossi MJ, D'Agostino RB Jr, Provencher MT, et al. Could the New England Journal of Medicine be biased against arthroscopic knee surgery? Arthroscopy 2014;30:536-7.

19 Lubowitz JH, Provencher MT, Rossi MJ. Could the New England Journal of Medicine be biased against arthroscopic knee surgery? Part 2. Arthroscopy 2014:30:654-5.

20 Kim S, Bosque J, Meehan JP, et al. Increase in outpatient knee arthroscopy in the United States: a comparison of national surveys of ambulatory surgery, 1996 and 2006. J Bone Joint Surg Am 2011;93:994-1000.

21 Bohensky MA, Sundararajan V, Andrianopoulos N, et al. Trends in elective knee arthroscopies in a population-based cohort, 2000-2009. Med J Aust 2012;197:399-403.

22 Harris IA, Madan NS, Naylor JM, et al. Trends in knee arthroscopy and subsequent arthroplasty in an Australian population: a retrospective cohort study. BMCMusculoskeletDisord 2013:14:143

23 Thorlund JB, Hare KB, Lohmander LS. Large increase in arthroscopic meniscus surgery in the middle-aged and older population in Denmark from 2000 to 2011. Acta Orthop 2014;85:287-92

24 Maletis GB, Inacio MC, Reynolds S, et al. Incidence of symptomatic venous thromboembolism after elective knee arthroscopy. J Bone Joint Surg Am 2012;94:714-20.

25 Hame SL, Nguyen V, Ellerman J, et al. Complications of arthroscopic meniscectomy in the older population. Am J Sports Med 2012;40:1402-5. 
26 Bohensky MA, Ademi Z, deSteiger R, et al. Quantifying the excess cost and resource utilisation for patients with complications associated with elective knee arthroscopy: a retrospective cohort study. Knee 2014;21:491-6.

27 Moher D, Liberati A, Tetzlaff J, et al, for the PRISMA Group. Preferred reporting items for systematic reviews and meta-analyses: the PRISMA statement. BMJ 2009;339:b2535.

28 Juhl $\mathrm{C}$, Lund $\mathrm{H}$, Roos EM, et al. A hierarchy of patient-reported outcomes for meta-analysis of knee osteoarthritis trials: empirical evidence from a survey of high impact journals. Arthritis 2012;2012:136245.

29 Higgins JP, Green S. Cochrane handbook for systematic reviews of interventions, version 5.1.0 (updated March 2011). Cochrane Collaboration, 2011.

30 Kellgren JH, Lawrence JS. Radiological assessment of osteo-arthrosis. Ann Rheum Dis 1957;16:494-502.

31 Ahlback S: Osteoarthrosis of the knee: a radiographic investigation. Acta Radiol Diagn (Stockh) 1968;suppl 277:7-72.

32 Hedges LV, Olkin I. Statistical methods for meta-analysis. Academic Press, 1985.

33 Higgins JP, Thompson SG. Quantifying heterogeneity in a metaanalysis. Stat Med 2002;21:1539-58

34 Higgins JP, Thompson SG, Deeks JJ, et al. Measuring inconsistency in meta-analyses. BMJ 2003;327:557-60.

35 Bliddal H, Christensen R. The treatment and prevention of knee osteoarthritis: a tool for clinical decision-making. ExpertOpin Pharmacother 2009;10: 1793-804.

36 Tubach F, Ravaud P, Baron G, et al. Evaluation of clinically relevant states in patient reported outcomes in knee and hip osteoarthritis: the patient acceptable symptom state. Ann Rheum Dis 2005;64:34-7.

37 Chinn S. A simple method for converting an odds ratio to effect size for use in meta-analysis. Stat Med 2000;19:3127-31.

38 Tubach F, Ravaud P, Baron G, et al. Evaluation of clinically relevant changes in patient reported outcomes in knee and hip osteoarthritis: the minimal clinically important improvement. Ann Rheum Dis 2005;64:29-33.

39 Merchan EC, Galindo E. Arthroscope-guided surgery versus nonoperative treatment for limited degenerative osteoarthritis of the femorotibial joint in patients over 50 years of age: a prospective comparative study. Arthroscopy 1993;9:663-7.

40 Moseley JB Jr, Wray NP, Kuykendall D, et al. Arthroscopic treatment of osteoarthritis of the knee: a prospective, randomized, placebo-controlled trial. Results of a pilot study. Am J Sports Med 1996;24:28-34.

41 Biedert RM. Treatment of intrasubstance meniscal lesions: a randomized prospective study of four different methods. Knee Surg Sports Traumatol Arthrosc 2000;8:104-8.

42 Kang JG, Wang ML, Zhang XN. Treatment of knee osteoarthritis with arthroscopic debridement and intra-articular sodium hyaluronate injection [Chinese]. Journal of Jilin University Medicine Edition 2005:802-5.

43 Aydogan NH, Baydar ML, Atay T, et al. The effect of arthroscopic surgery and intraarticular drug injection to the antioxidation system and lipid peroxidation at osteoarthritis of knee. Saudi Med J 2008;29:397-402.

44 Vermesan D, Prejbeanu R, Laitin S, et al. Arthroscopic debridement compared to intra-articular steroids in treating degenerative medial meniscal tears. Eur Rev Med Pharmacol Sci 2013;17:3192-6.

45 Hitzeman N, Masley C. Arthroscopic surgery for knee osteoarthritis. Am Fam Physician 2008;78:331-2.

46 Lubowitz JH, Provencher MT, Poehling GG. Cartilage treatment and biologics current research. Arthroscopy 2013;29:1597-8

47 Herrlin SV, Wange PO, Lapidus G, et al. Is arthroscopic surgery beneficial in treating non-traumatic, degenerative medial meniscal tears? A five year follow-up. Knee Surg Sports Traumatol Arthrosc 2013;21:358-64

48 Dahl OE, Gudmundsen TE, Haukeland L. Late occurring clinical deep vein thrombosis in joint-operated patients. Acta Orthop Scand 2000;71:47-50.

49 Delis KT, Hunt N, Strachan RK, et al. Incidence, natural history, risk factors of deep vein thrombosis in elective knee arthroscopy. Thromb Haemost 2001;86:817-21.

50 Crevoisier $X$, Munzinger U, Drobny T. Arthroscopic partial meniscectomy in patients over 70 years of age. Arthroscopy 2001;17:732-6.

51 Shannon FJ, Devitt AT, Poynton AR, et al. Short-term benefit of arthroscopic washout in degenerative arthritis of the knee. IntOrthop 2001;25:242-5.

52 Wirth T, Schneider B, Misselwitz F, et al. Prevention of venous thromboembolism after knee arthroscopy with low-molecular weight heparin (reviparin): results of a randomized controlled trial. Arthroscopy 2001;17:393-9.

53 Bergqvist $D$, Lowe $G$. Venous thromboembolism in patients undergoing laparoscopic and arthroscopic surgery and in leg casts. Arch Intern Med 2002;162:2173-6

54 Kim TK, Savino RM, McFarland EG, et al. Neurovascular complications of knee arthroscopy. Am J Sports Med 2002;30:619-29.

55 Michot M, Conen D, Holtz D, et al. Prevention of deep-vein thrombosis in ambulatory arthroscopic knee surgery: a randomized trial of prophylaxis with low-molecular weight heparin. Arthroscopy 2002;18:257-63.

56 Wai EK, Kreder HJ, Williams JI. Arthroscopic debridement of the knee for osteoarthritis in patients fifty years of age or older: utilization and outcomes in the province of Ontario. J Bone Joint Surg Am 2002;84-A:17-22.
57 Widuchowski J, Koczy B, Widuchowski W. [Intra- and postoperative complications in the arthroscopy of the knee joint.] ChirNarzadow Ruchu Ortop Pol 2003;68:105-8.

58 Sgaglione NA. Complications of meniscus surgery. Sports Med Arthrosc 2004;12:148-59.

59 Ilahi OA, Reddy J, Ahmad I. Deep venous thrombosis after knee arthroscopy: a meta-analysis. Arthroscopy 2005;21:727-30.

$60 \mathrm{Ng}$ WM, Chan KY, Lim AB, et al. The incidence of deep venous thrombosis following arthroscopic knee surgery. Med J Malaysia 2005;60(suppl C):14-6.

61 Engbaek J, Bartholdy J, Hjortso NC. Return hospital visits and morbidity within 60 days after day surgery: a retrospective study of 18,736 day surgical procedures. ActaAnaesthesio/Scand 2006;50:911-9.

62 Ettema HB, Hoppener MR, Veeger NJ, et al. Low incidence of venographically detected deep vein thrombosis after knee arthroscopy without thromboprophylaxis: a prospective cohort study. J Thromb Haemost 2006;4:1411-3.

63 Reigstad 0, Grimsgaard C. Complications in knee arthroscopy. Knee Surg Sports Traumatol Arthrosc 2006;14:473-7

64 Camporese G, Bernardi E, Prandoni P, et al. Low-molecular-weight heparin versus compression stockings for thromboprophylaxis after knee arthroscopy: a randomized trial. Ann Intern Med 2008;149:73-82.

65 Ramos J, Perrotta C, Badariotti G, et al. Interventions for preventing venous thromboembolism in adults undergoing knee arthroscopy. Cochrane Database Syst Rev 2008;4:CD005259.

66 Rodriguez Moreno HA, Hortua P, Rocha C, et al. Risk of deep vein thrombosis in patients undergoing knee arthroscopy. Curr Orthop Pract 2009;20:665-8.

67 Yacub JN, Rice JB, Dillingham TR. Nerve injury in patients after hip and knee arthroplasties and knee arthroscopy. Am J Phys Med Rehabil 2009;88:635-41; quiz 42-4, 91.

68 Tzoanos GN, Manidakis N, Koutroumpas I, et al. Knee arthroscopy under local anesthesia: the Crete experience. Arthroscopy Journal of Arthroscopic and Related Surgery Conference: 8th Biennial Congress of International Society of Arthroscopy, Knee Surgery, and Orthopaedic Sports Medicine, ISAKOS, 2011;27.

69 Bohensky M, Sundararajan V, Andrianopoulos N, et al. Adverse outcomes associated with knee arthroscopy in Victoria, Australia from 2000-2009. Internal Medicine Journal Conference: 53rd Annual Scientific Meeting of the Australian Rheumatology Association in Conjunction with Rheumatology Health Professionals Canberra, ACT Australia Conference Start, 2012;42.

70 Bohensky MA, deSteiger R, Kondogiannis C, et al. Adverse outcomes associated with elective knee arthroscopy: a population-based cohort study. Arthroscopy 2013;29:716-25.

71 Dias L, Pereira A, Marcos A. Spinal anesthesia for ambulatory surgery-24 hours postoperative follow-up. Regional Anesthesia and Pain Medicine Conference: 32nd Annual European Society of Regional Anaesthesia and Pain Therapy, ESRA Congress, 2013;38.

72 Greene JW, Deshmukh AJ, Cushner FD. Thromboembolic complications in arthroscopic surgery. Sports Med Arthrosc 2013;21:69-74.

73 Martin CT, Pugely AJ, Gao Y, et al. Risk factors for thirty-day morbidity and mortality following knee arthroscopy: a review of 12,271 patients from the national surgical quality improvement program database. J Bone Joint Surg Am 2013;95:e98 1-10.

74 Mauck KF, Froehling DA, Daniels PR, et al. Incidence of venous thromboembolism after elective knee arthroscopic surgery: a historical cohort study. J Thromb Haemost 2013:11:1279-86.

75 Salzler MJ, Lin A, Miller CD, et al. Complications after arthroscopic knee surgery. Am J Sports Med 2014:42:292-6.

76 Hetsroni I, Lyman S, Do H, et al. Symptomatic pulmonary embolism after outpatient arthroscopic procedures of the knee: the incidence and risk factors in 418,323 arthroscopies. J Bone Joint Surg Br 2011;93:47-51.

77 Jameson SS, Dowen D, James $\mathrm{P}$, et al. The burden of arthroscopy of the knee: a contemporary analysis of data from the English NHS. J Bone Joint Surg $\mathrm{Br}$ 2011;93:1327-33.

78 Yeranosian MG, Petrigliano FA, Terrell RD, et al. Incidence of postoperative infections requiring reoperation after arthroscopic knee surgery. Arthroscopy 2013:29:1355-61.

79 Hoppener MR, Ettema HB, Henny CP, et al. Low incidence of deep vein thrombosis after knee arthroscopy without thromboprophylaxis: a prospective cohort study of 335 patients. Acta Orthop 2006;77:767-71.

80 Laupattarakasem W, Laopaiboon M, Laupattarakasem P, et al. Arthroscopic debridement for knee osteoarthritis. Cochrane Database Syst Rev 2008;1: CD005118.

81 Khan M, Evaniew N, Bedi A, et al. Arthroscopic surgery for degenerative tears of the meniscus: a systematic review and meta-analysis. CMAJ 2014;186: 1057-64.

82 Kaptchuk TJ, Goldman P, Stone DA, et al. Do medical devices have enhanced placebo effects? J Clin Epidemiol 2000;53:786-92.

83 Zhang W, Robertson J, Jones AC, et al. The placebo effect and its determinants in osteoarthritis: meta-analysis of randomised controlled trials. Ann Rheum Dis 2008;67:1716-23. 
84 Kaptchuk TJ, Stason WB, Davis RB, et al. Sham device v inert pill: randomised controlled trial of two placebo treatments. BMJ 2006;332:391-7.

85 Bannuru RR, Schmid CH, Sullivan MC, et al. Differential response of placebo treatments in osteoarthritis trials: a systematic review and network meta-analysis. Osteoarthritis Cartilage 2014;22(suppl):S24-5.

86 Juhl C, Christensen R, Roos EM, et al. Impact of exercise type and dose on pain and disability in knee osteoarthritis: a systematic review and meta-regression analysis of randomized controlled trials. Arthritis Rheumatol 2014;66:622-36.

87 Golder S, Loke YK, Bland M. Meta-analyses of adverse effects data derived from randomised controlled trials as compared to observational studies: methodological overview. PLoSMed 2011;8:e1001026.

88 Liu CJ, Latham NK. Progressive resistance strength training for improving physical function in older adults. Cochrane Database Syst Rev 2009;3:CD002759.

89 Zhang W, Nuki G, Moskowitz RW, et al. OARSI recommendations for the management of hip and knee osteoarthritis: part III. Changes in evidence following systematic cumulative update of research published through January 2009. Osteoarthritis Cartilage 2010;18:476-99.

90 Special report: measuring and reporting pain outcomes in randomized controlled trials. Technol Eval Cent Assess Program Exec Summ 2006;21:1-2.

91 Wartolowska K, Judge A, Hopewell $S$, et al. Use of placebo controls in the evaluation of surgery: systematic review. BMJ 2014;348:g3253.

92 Lim HC, Adie S, Naylor JM, et al. Randomised trial support for orthopaedic surgical procedures. PLoS One 2014;9:e96745.

93 Englund M, Roos EM, Roos HP, et al. Patient-relevant outcomes fourteen years after meniscectomy: influence of type of meniscal tear and size of resection. Rheumatology (Oxford) 2001;40:631-9.
94 Lohmander LS, Englund PM, Dahl LL, et al. The long-term consequence of anterior cruciate ligament and meniscus injuries: osteoarthritis. Am.JSports Med 2007;35:1756-69.

95 Bedi A, Kelly NH, Baad M, et al. Dynamic contact mechanics of the medial meniscus as a function of radial tear, repair, and partial meniscectomy. J Bone Joint Surg Am 2010;92:1398-408.

96 Brophy RH, Gray BL, Nunley RM, et al. Total knee arthroplasty after previous knee surgery: expected interval and the effect on patient age. J Bone Joint Surg Am 2014;96:801-5.

97 McAlindon TE, Bannuru RR, Sullivan MC, et al. OARSI guidelines for the non-surgical management of knee osteoarthritis. Osteoarthritis Cartilage 2014;22:363-88.

98 Prasad V, Cifu A, loannidis JP. Reversals of established medical practices: evidence to abandon ship. JAMA 2012;307:37-8.

99 Luetmer MT, Kallmes DF. Have referral patterns for vertebroplasty changed since publication of the placebocontrolled trials? AJNR Am J Neuroradiol 2011;32:647-8.

100 Mitchell JM. Effect of physician ownership of specialty hospitals and ambulatory surgery centers on frequency of use of outpatient orthopedic surgery. Arch Surg 2010;145:732-8.

101 Birkmeyer JD, Reames BN, McCulloch $\mathrm{P}$, et al. Understanding of regional variation in the use of surgery. Lancet 2013;382:1121-9.

102 Price A, Beard D. Arthroscopy for degenerate meniscal tears of the knee. BMJ 2014;348:g2382.

103 Lohmander LS, Roos EM. The evidence base for orthopaedics and sports medicine. BMJ 2015;350:g7835. 